\title{
Correlation between age, muscle thickness, spasticity and functional ability in children with spastic hemiplegic cerebral palsy
}

\author{
Mostafa S. Ali ${ }^{*}$, Faten H. Abdel- Azim² and Aya Ahmed A. Ali ${ }^{3}$
}

*Correspondence: drmostafamalak9912@gmail.com

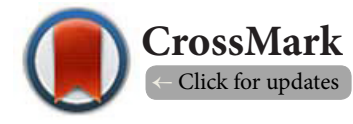

\begin{abstract}
'Lecturer at department of Physical Therapy for pediatrics, Faculty of Physical Therapy, Cairo University, Egypt. 2Professor at department of Physical Therapy for pediatrics, Faculty of Physical Therapy, Cairo University, Egypt. ${ }^{3}$ Instructor at department of Physical Therapy for pediatrics, Deraya University, Elmina, Egypt.
\end{abstract}

\begin{abstract}
Background: Children with spastic hemiplegia had disabilities of the upper extremities such as reaching, grasping, and object manipulation resulting in dependency in daily activities and a lack of successful social integration.Muscle morphology and structures are different in children with cerebral palsy as a result of secondary impairments such as disuse,spasticity, and immobilization.

Purpose: To investigate the correlations between spasticity, functional ability and muscle thickness of biceps brachii in children with spastic hemiplegic cerebral palsy and to compare muscle thickness in normal children and spastic hemiplegic cerebral palsy children.

Methods: 40 children from both sexes with age ranged from 2 to 5 years included in this study and divided into two equal groups. Group (A) included 20 aged matched normal developmental children and Group (B) included 20 children with hemiplegic cerebral palsy. Muscle thickness of biceps brachiiwas measured with ultrasound imaging. The functional ability was evaluated using the Gross Motor Function Measurement-88 (GMFM-88). The spasticity was evaluated with the Modified Ashworth Scale (MAS).

Results: The results of the study revealed that there was a significant difference of biceps brachii thickness between normal group and spastic hemiplegic cerebral palsy group $(\mathrm{P} \leq 0.05)$. For correlation, there was positive significant correlation $(\mathrm{r}=-0.765 ; \mathrm{p}<0.0001)$ between spasticity and functional ability. But there was no significant correlation between age and muscle thickness, spasticity and functional ability. Also, there was no significant statistical correlation between muscle thickness and function ability.
\end{abstract}

Conclusion: In children with spastic cerebral palsy, muscle thickness of biceps brachii was less than in age-matched normal children. Furthermore, Children with hemiplegic cerebral palsy may need muscle strengthening exercises in the upper extremities, including the biceps muscle. Therefore prevent muscle atrophy and increase functional daily living activities.

Keywords: Cerebral palsy, Hemiplegia, Muscle thickness, Spasticity, Functional ability

\section{Introduction}

Cerebral palsy (CP) is defined as a group of permanent developmental disorders of movement and posture, leading toactivity limitations, which are attributed to non-progressive disturbances in the immature fetal or infant brain [1]. The spastic muscles are frequently shorterthan normaldue to insufficient stretching. Manystudies have revealed that the spasticity and limited activity causing weakness, atrophy and muscle imbalance as a result of reduced joint range of motion, disuse and contracture $[2,3]$. The motor control, cognitive and associated disorderswith CP children causing challenging to measure the muscular strength of children; so, researches has been directed to study morphology and structures of muscles in children with CP $[4,5]$ that are altered to some degree in children with $\mathrm{CP}$ as a result of second- 
ary impairments such as disuse, spasticity, and immobilization $[6,7]$. There is consequent reliable evidence that the size of the muscles in the paretic limbs, which include muscle thickness, volume and cross-sectional area, is less when compared to non-paretic muscles and normal developing muscles [5]. Inactivity and disuse cycle occurred in children and teen-agers with $\mathrm{CP}$ are permanent due to the progressive development of weakness and contractures, that leading to a significant progressive disability over lifespan of children $[4,8]$. A previous study revealed that the muscle structures changes are directly related to motor functions in older children, adolescents, and adults with CP $[9,10]$. Moreover, this relationship is also associated with muscle thickness (MT) in children and adults with $\mathrm{CP}$ that measures quantitative muscle evaluation and show direct positive relationship with activity [5,9]. However, it remains unclear when the structure of the muscle begins to change in children with $\mathrm{CP}$ and these changes progress with time. In addition, there is little information about the influence of the muscle structures on motor functions in young children with CP. Ultrasound imaging has recently become more widely used in musculoskeletal research and evaluation because it is a relatively useful, quick, cheap and child-friendly assessment tool [11], although it provides only superficial data for the muscle region [12] as compared to diffusion tensor imaging which isa magnetic resonance imaging technique that enables the measurement of the restricted diffusion of water in tissue in order to produce neural tract images instead of using this data solely for the purpose of assigning contrast or colors to pixels in a cross sectional image. It also provides useful structural information about muscle and high-resolution anatomical MRI scans. Other reviews suggested that muscle thickness, length and volume tend to be smaller in children with $\mathrm{CP}[5,7]$. However, these studies have provided very limited data about muscle architecture in children with $\mathrm{CP}$ $[5,7,8,13,14]$. The aim of this study was to investigate correlations between age, functional ability, muscle thickness and spasticity in children with spastic hemiplegic C Pand to compare biceps muscle thickness between normal children and hemiplegic cerebral palsy children.

\section{Material and methods}

\section{Study design:cross-sectional correlational design}

The study was held between august 2018 and November 2018. An informed consent form and agreement was obtained from their parents for participation of their children in the study. An ethical approval was granted by ethical committee- faculty of physical therapy (NO.P.T.REC|012|002058) and the aim and steps of the task were explained to them. Two study groups (normal and hemiplegic cerebral palsy) were assessed by ultrasonography to measure biceps brachii muscle thickness.

\section{Participants}

Eighty-four patients were initially enrolled. However, 8 patients were excluded (5, owing to having upper limb surgeries, 3 children' parents refused to participate in the study). A flow chart describing the distribution of participants is shown in (Figure 1). Forty children from both sexes were selected from the outpatient clinic of the faculty of Physical therapy and AL-Minia physiotherapy clinic and divided into two equal groups. Group (A) included twenty age-matched normal children and group (B) included twenty hemiplegic cerebral palsy children with spasticity grade 1 and $1+$ according to modified ashowrth scale.The children were recruited for this study upon fulfilling the following inclusion criteria: (1) the participant was diagnosed with spasti chemipelgic CP and (2) the participant aged from 2 to 5 years old. The exclusion criteria for this study were as follows: (1) CP associated with muscular disease, (2) previous history of muscle trauma, (3) previous history of surgical intervention of the upper extremities, (4) previous history of chemo therapy within 6 months, (5) Recent skin injury, (6) Bony structure causing joint limitation, The age-matched children with normal developing muscles were recruited for this study as group (A) and able to use upper limb independently; potential participants were excluded if they had any developmental disorder affecting the upper limbs.

\section{Measurement procedures \\ Evaluation of spasticity}

By using the modified Ashworth scale. All children selected for this study were grade 1 and $1+$ of spasticity [15].

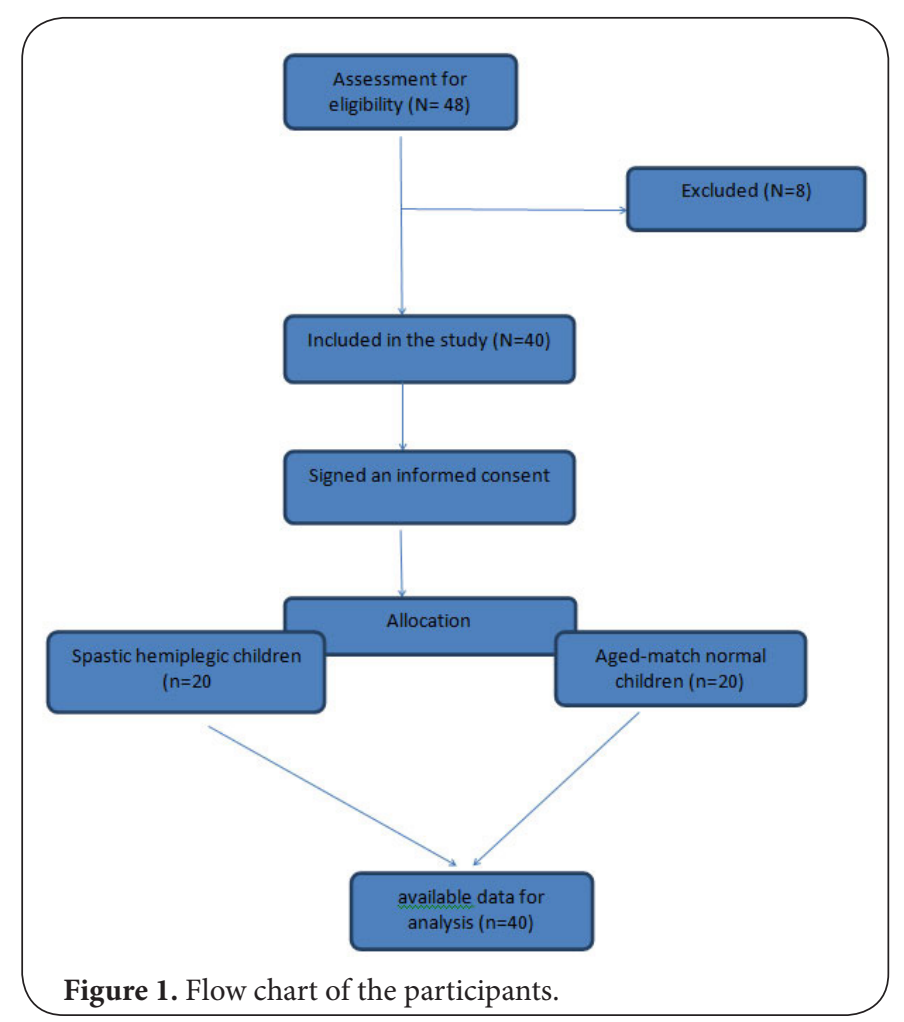




\section{Measurement of muscle thickness}

Thickness of biceps brachii was measured with ultrasonography device $(7.5 \mathrm{MHz}$ ultrasound transducer probe with serial number AGC73124954). At first, the child was positioned in supine with extended elbow. A longitudinal section image was taken by ultrasonography for the biceps muscle while the researcher was seated beside the patient to support the upper limb as needed. After capturing the images by ultrasonography, the researcher measured Muscle thickness of biceps brachii by measuring a distance by drawing a vertical line between the superficial aponeurosis and the deep aponeurosis Figures 2 and 3. During the measurement, great care was taken to maintain
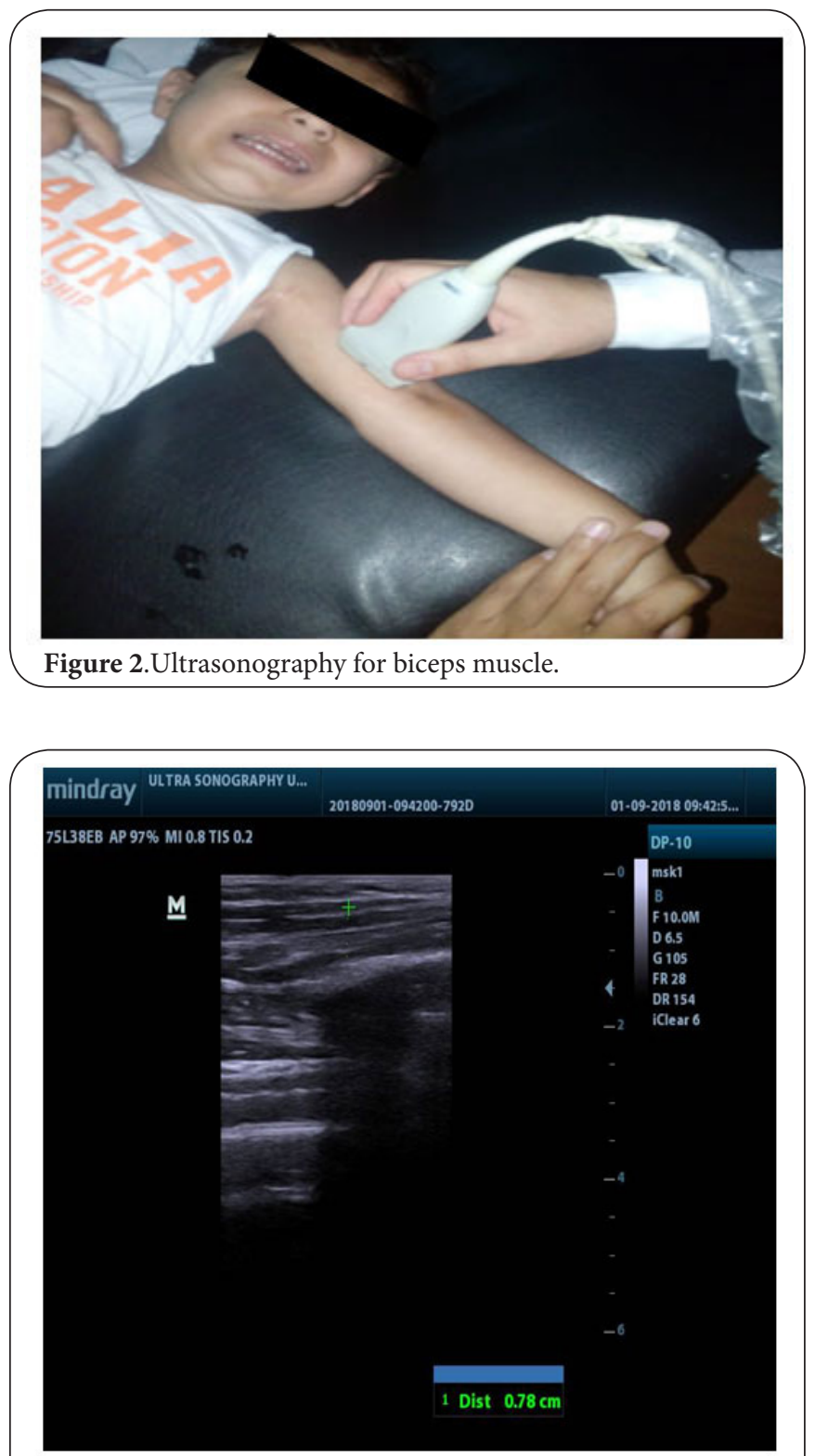

Figure 3. Measurement of muscle thickness of biceps muscle by ultrasonography. the practical individuals in a standardized position. The pressure of the transducer was kept to a minimum by using enough amount of contact gel, and by observing the measured realtime ultrasonic images as noted, to eliminate distortion of the skin and subcutaneous tissues due to excess compression [16]. All muscle thickness measurements were performed by the same practical individuals [17].

\section{Gross Motor Function Measurement-88 (GMFM-88)}

The activity limitations of children were evaluated by (GMFM88). The GMFM-88 is a criterion-referenced observational measure for the assessment of children with CP [18]; it consists of 88 items divided into five dimensions: lying and rolling; sitting; crawling and kneeling; standing; and walking, running, and jumping. The scale was therefore proposed to quantitatively evaluate gross motor function of the participants. The score for each dimension is expressed as a percentage of the maximum score for that dimension as analyzed in this study. The total score iscalculated by averaging the percentage scores across the five dimensions, range from 0 to 100 .

\section{Data Analysis}

Statistical Package for Social Sciences (SPSS) computer program (version 20 windows) was used for data analysis. P value $\leq 0.05$ was considered significant. Numerical data were explored for normality by checking the distribution data using tests of normality (Kolmogorov-smirnov and shapiro-wik tests). For parametric data (muscle thickness); unpaired t-test was used to identify statistical difference between groups. Spearman's rank correlation was used to detect the significant correlation between age, spasticity, muscle thickness, and GMFM.

\section{Results}

As shown in Table 1, the results revealed that there was a significant difference between normal group and spastic group $(P=0.0023)$.

As shown in Table 2, there was no significant statistical correlation between age and spasticity $(\mathrm{P}=0.417)$, between age and functional ability $(P=0.851)$, between age and biceps brachiithickness ( $P=0.493)$, between spasticity and biceps brachiithickness ( $P=0.423)$, and between biceps brachiithickness and function ability $(P=0.609)$. In contrast, there was a significant correlation between spasticity and functional ability $(\mathrm{P}=0.000)$.

Table 1. Comparison between both groups regarding Muscle thickness.

\begin{tabular}{lllll}
\hline $\begin{array}{l}\text { Muscle } \\
\text { thickness }\end{array}$ & $\begin{array}{l}\text { Normal } \\
(\mathbf{n}=\mathbf{2 0}) \\
\text { Mean } \pm \text { SD }\end{array}$ & $\begin{array}{l}\text { Spastic } \\
(\mathbf{n}=\mathbf{2 0}) \\
\text { Mean } \pm \text { SD }\end{array}$ & t-value & P-value \\
\hline $\begin{array}{l}\text { Biceps brachii } \\
\text { muscle thickness }\end{array}$ & $1.387 \pm 0.277$ & $1.048 \pm 0.317$ & 3.3065 & $0.0023(\mathrm{~S})$ \\
\hline \multicolumn{2}{l}{$\mathrm{S}=\mathrm{p}<0.05=$ Significant } & & & \\
\hline
\end{tabular}


Table 2. Correlation between different parameters in spastic group.

\begin{tabular}{llll}
\hline & Age & Spasticity & GMFM \\
\hline Spasticity Spearman's rank Corr. & -0.1927 & 1 & -0.765 \\
Sig. (2 tailed) & 0.417 &. & 0.000 \\
\hline GMFM Spearman's rank Corr. & 0.044 & -0.765 & 1 \\
Sig. (2 tailed & 0.851 & 0.000 &. \\
\hline Muscle thickness Spearman's rank Corr. & 0.162 & 0.191 & -0.122 \\
Sig. (2 tailed & 0.493 & 0.423 & 0.609 \\
\hline
\end{tabular}

\section{Discussion}

Children with spastic hemiplegia had disabilities of the upper extremities such as reaching, grasping, and object manipulation resulting in dependency in daily activities and a lack of successful social integration. Spasticity and activity limitationscontribute to muscle weakness, imbalance and muscle atrophy resulting from disuse, muscle contracture and a reduced joint range of motionso this study was aimed to investigate the correlations between spasticity, functional ability and MT of biceps brachii in children with spastic hemiplegic cerebral palsy and also to compare muscle thickness in normal children and children with spastic hemiplegic cerebral palsy. The results demonstrated a direct correlation between spasticity of biceps brachii and GMFM-88 and non-significant relation between MT and GMFM-88 in addition to no relation between spasticity and MT of biceps brachii. Finally there is no relation between age and all mention measures above. In the present study, the MT of biceps brachii was found to be significantly less in children who were aged from 2 to 5 years old with spastic hemiplegic CP than in normal age-matched children.

The results of current study are consistent with mockford and Caulton, 2010 who concluded that normal muscle is composed of $95 \%$ fibers but spastic muscle is only $40 \%$ fibers with increased intramuscular fat and connective tissue [19]. Skeletal muscles are reshaped and can be altered by several factors that may be positive or negative such as disuse, hypertonia (spasticity), strength training and immobilization $[9,20]$. Results in animal and human models $[14,21]$ have revealed that muscle thickness and architecture become smaller due to disuse and immobilization which may lead to muscle weakness and muscle imbalance $[8,14,22,23]$. A previous study suggested that changes of muscle thickness and length might occur at an earlier age [24]. Thus, the first priority of children with $\mathrm{CP}$ is to perform early activities to enhance these adaptive changes in muscle architecture and functions. The results of this study show that the thickness of the affected biceps brachii is less in hemiplegic cerebral palsy children as a result of immobilization that progress to muscle fibrosis that reduce muscle elasticity and muscle strength [25]. According to the results, there was no significant correlation between the MT of biceps brachii and GMFM-88 in spastic hemiplegic children with CP. However, we noted in this study that MT was significantly reduced. These results can be assumed that there is little difference at a young age
(2-5 years), but the correlation between MT and GMFM-88 may change by time during the growth period due to lower mobility, disuse atrophy and muscle weakness. Furthermore, these differences were related to the changes of gross motor functions.So, proper exercise program designed to improve muscle strength during the growth spurt may be required. Therefore, the results of this study couldn't detect time of muscle thickness to change with age so, large sample sizes will be required to generalize this result, and make further predictions and assumptions to investigate the relation of muscle thickness with age in children. The correlations of MT and functional ability were evaluated in this study. However, it is not clear whether the MT determines functional level in spastic hemiplegic $\mathrm{CP}$, or disuse and lower gross motor function lead to muscle atrophy. Although CP is non-progressive lesion, it associated with secondary muscular impairments such as muscle weakness which might cause reduction of muscle volume and length [5]. The motor function impairments in hemiplegic CP children could contribute to development of muscle weakness and contracture that are complex in these children, but the results of another study revealed that the combination of different neural mechanisms and muscular factors cause progression of muscle architecture changes $[5,26]$. Muscle weakness isn't the only cause of reduced muscle size, but also reduced muscle activation and increased co-activation of case might lead to reduction of muscle size [27]. Therefore, the degree of muscle development may determine the level of functional ability in the early stages of CP. Ultrasonography is a useful method of muscle imaging and used to measure MT and length in children with CP [13]. Sonographic measurement may be used overwide range of contractions. finaly, there is no correlation between muscle thickness and functinal activity for some muscles, so ultrasonographic measures of thickness cannot be used to detect activity in these muscles [28] The results of the current study comes in agreement with [29] who found that the affected side of stroke patients showed reduced muscle thickness and fascicle length compared to the unaffected side.

\section{Limitation of study}

1. Measurements were performed on only one standardized area per muscle; it has been shown that muscle architecture can vary throughout its length

2. The study was limited to evaluate MT in children while 
other muscle structures were not evaluated as muscle fascicle length and the pennation angle.

3. The study was limited to evaluate biceps brachii only.

4. Small sample size of the participant population.

\section{Conclusion}

Finally there is significant difference of muscle thickness between normal and children with hemiplegic cerebral palsy that may need muscle strengthening exercises in the upper extremities, including the biceps muscle in children with CP. therefore prevent muscle atrophy and increase functional daily living activities.

\section{Competing interests}

The authors declare that they have no competing interests.

Authors' contributions

\begin{tabular}{|l|c|c|c|}
\hline Authors' contributions & MSA & FHZ & AAA \\
\hline Research concept and design & $\checkmark$ & $\checkmark$ & $\checkmark$ \\
\hline Collection and/or assembly of data & $\checkmark$ & $\checkmark$ & -- \\
\hline Data analysis and interpretation & $\checkmark$ & $\checkmark$ & $\checkmark$ \\
\hline Writing the article & $\checkmark$ & $\checkmark$ & -- \\
\hline Critical revision of the article & $\checkmark$ & $\checkmark$ & $\checkmark$ \\
\hline Final approval of article & $\checkmark$ & $\checkmark$ & $\checkmark$ \\
\hline Statistical analysis & $\checkmark$ & $\checkmark$ & $\checkmark$ \\
\hline
\end{tabular}

\section{Acknowledgment}

The authors would like to express their appreciation to all children and their parents who participated in this study with cooperation.

Publication history

Editor: Gordon John Alderink, Grand Valley State University, USA. Received: 21-Apr-2019 Final Revised: 07-Jun-2019

Accepted: 12-Jun-2019 Published: 20-Jun-2019

\section{References}

1. Bax M, Goldstein M, Rosenbaum P, Leviton A, Paneth N, Dan B, Jacobsson $B$ and Damiano D. Proposed definition and classification of cerebral palsy, April 2005. Dev Med Child Neurol. 2005; 47:571-6. I PubMed

2. Gracies JM. Pathophysiology of spastic paresis. I: Paresis and soft tissue changes. Muscle Nerve. 2005; 31:535-51. | Article | PubMed

3. Wren TA, Do KP and Kay RM. Gastrocnemius and soleus lengths in cerebral palsy equinus gait--differences between children with and without static contracture and effects of gastrocnemius recession. J Biomech. 2004; 37:1321-7. | Article | PubMed

4. Moreau NG, Teefey SA and Damiano DL. In vivo muscle architecture and size of the rectus femoris and vastus lateralis in children and adolescents with cerebral palsy. Dev Med Child Neurol. 2009; 51:800-6. | Article | PubMed Abstract | PubMed FullText

5. Barrett RS and Lichtwark GA. Gross muscle morphology and structure in spastic cerebral palsy: a systematic review. Dev Med Child Neurol. 2010; 52:794-804. | Article | PubMed

6. Williams PE and Goldspink $G$. The effect of immobilization on the longitudinal growth of striated muscle fibres. J Anat. 1973; 116:45-55. | PubMed Abstract | PubMed FullText

7. Kwah LK, Pinto RZ, Diong $\mathrm{J}$ and Herbert RD. Reliability and validity of ultrasound measurements of muscle fascicle length and pennation in humans: a systematic review. J Appl Physiol (1985). 2013; 114:761-9. | Article | PubMed

8. Barber L, Hastings-Ison T, Baker R, Barrett R and Lichtwark G. Medial gastrocnemius muscle volume and fascicle length in children aged $\mathbf{2}$ to 5 years with cerebral palsy. Dev Med Child Neurol. 2011; 53:543-8.

9. Ohata K, Tsuboyama T, Haruta T, Ichihashi N, Kato T and Nakamura T. Relation between muscle thickness, spasticity, and activity limitations in children and adolescents with cerebral palsy. Dev Med Child Neurol. 2008; 50:152-6.

10. Ohata K, Tsuboyama T, Ichihashi N and Minami S. Measurement of muscle thickness as quantitative muscle evaluation for adults with severe cerebral palsy. PhysTher. 2006; 86:1231-9.

11. Deffieux T, Gennisson JL, Tanter M and Fink M. Assessment of the mechanical properties of the musculoskeletal system using 2-D and 3-D very high frame rate ultrasound. IEEE Trans Ultrason Ferroelectr Freq Control. 2008; 55:2177-90. | Article | PubMed

12. Bolsterlee B, Veeger HE, van der Helm FC, Gandevia SC and Herbert RD. Comparison of measurements of medial gastrocnemius architectural parameters from ultrasound and diffusion tensor images. J Biomech. 2015; 48:1133-40. | Article | PubMed

13. Shortland AP, Harris CA, Gough M and Robinson RO. Architecture of the medial gastrocnemius in children with spastic diplegia. Dev Med Child Neurol. 2002; 44:158-63. I Article I PubMed

14. Noble JJ, Fry NR, Lewis AP, Keevil SF, Gough M and Shortland AP. Lower limb muscle volumes in bilateral spastic cerebral palsy. Brain Dev. 2014; 36:294-300. | Article | PubMed

15. Bohannon RW and Smith MB. Interrater reliability of a modified Ashworth scale of muscle spasticity. Phys Ther. 1987; 67:206-7. | Article I PubMed

16. Benard MR, Becher JG, Harlaar J, Huijing PA and Jaspers RT. Anatomical information is needed in ultrasound imaging of muscle to avoid potentially substantial errors in measurement of muscle geometry. Muscle Nerve. 2009; 39:652-65. | Article | PubMed

17. Reeves ND, Maganaris CN and Narici MV. Ultrasonographic assessment of human skeletal muscle size. Eur J Appl Physiol. 2004; 91:116-8. | Article | PubMed

18. Russell DJ, Avery LM, Rosenbaum PL, Raina PS, Walter SD and Palisano RJ. Improved scaling of the gross motor function measure for children with cerebral palsy: evidence of reliability and validity. Phys Ther. 2000; 80:873-85. | PubMed

19. Mockford M and Caulton JM. The pathophysiological basis of weakness in children with cerebral palsy. Pediatr Phys Ther. 2010; 22:222-33. | Article | PubMed

20. Rose $\mathrm{J}$ and McGill KC. Neuromuscular activation and motor-unit firing characteristics in cerebral palsy. Dev Med Child Neurol. 2005; 47:329-36. I PubMed

21. Bland DC, Prosser LA, Bellini LA, Alter KE and Damiano DL. Tibialis anterior architecture, strength, and gait in individuals with cerebral palsy. Muscle Nerve. 2011; 44:509-17. | Article | PubMed Abstract | PubMed FullText

22. Moreau NG, Falvo MJ and Damiano DL. Rapid force generation is impaired in cerebral palsy and is related to decreased muscle size and functional mobility. Gait Posture. 2012; 35:154-8. | Article | PubMed Abstract | PubMed FullText

23. Bodine SC. Disuse-induced muscle wasting. Int J Biochem Cell Biol. 2013; 45:2200-8. | Article | PubMed Abstract | PubMed FullText

24. Mathewson MA and Lieber RL. Pathophysiology of muscle contractures in cerebral palsy. Phys Med Rehabil Clin N Am. 2015; 26:57-67. | Article | PubMed Abstract | PubMed FullText

25. Ponten $\mathrm{E}$, Lindstrom $\mathrm{M}$ and Kadi F. Higher amount of MyHC IIX in a wrist flexor in tetraplegic compared to hemiplegic cerebral palsy. J Neurol Sci. 2008; 266:51-6. | Article | PubMed

26. Poon DM and Hui-Chan CW. Hyperactive stretch reflexes, co-contraction, and muscle weakness in children with cerebral palsy. Dev Med Child Neurol. 2009; 51:128-35. | Article | PubMed 
Ali et al, Physical Therapy and Rehabilitation 2019,

http://www.hoajonline.com/journals/pdf/2055-2386-6-8.pdf

27. Stackhouse SK, Binder-Macleod SA and Lee SC. Voluntary muscle activation, contractile properties, and fatigability in children with and without cerebral palsy. Muscle Nerve. 2005; 31:594-601.

28. Narici M. Human skeletal muscle architecture studied in vivo by noninvasive imaging techniques: functional significance and applications. $J$ Electromyogr Kinesiol. 1999; 9:97-103. | Article | PubMed

29. Yasar E, Adiguzel E, Kesikburun S, Yenihayat I, Yilmaz B, Alaca R and Tan AK. Assessment of forearm muscle spasticity with sonoelastography in patients with stroke. Br J Radiol. 2016; 89:20160603. | Article | PubMed Abstract | PubMed FullText

\section{Citation:}

Ali MS, Abdel-Azim FH and Ali AAA. Correlation between age, muscle thickness, spasticity and functional ability in children with spastic hemiplegic cerebral palsy. Phys Ther Rehabil. 2019; 6:8.

http://dx.doi.org/10.7243/2055-2386-6-8 